\title{
A new methodological approach to achieving adaptive coordination in the transport and logistics system of a smart city
}

\author{
Victor Katochkov, Gleb Savin*, and Valeria Grishina \\ Ural State University of Economics, 8 Marta St., 62, Yekaterinburg, Russia
}

\begin{abstract}
The paper considers the necessity of developing a new approach to achieving coordinated interactions between economic agents in the framework of the transport and logistics system (TLS) of a smart city; the following reasons being stressed: first, in the context of digitalization in logistics, the current approaches do not fully meet the present and future needs of evolutionary development; secondly, the current theoretical foundations of coordination do not allow to radically change its key indicators and ensure higher rates of economic growth, as well as an improvement in the quality of human life; thirdly, the current trend in the formation of TLS does not allow us to propose a more balanced vector of its development to provide adaptive coordination with the norms and rules of interaction of economic agents now. In spite of a great variety of research approaches, there is a need to propose a new approach to achieve adaptive coordination of flow processes within the framework of evolutionary-institutional economic theory leading to a higher level of interaction and economic growth
\end{abstract}

\section{Introduction}

Nowadays digitalization [1-2] is considered to be the only possible way to optimize and rationalize developing the socio-economic system; routine operations being replaced everywhere, transport and logistics systems of smart cities included.

When predicting the development of technologies [3-4] that can radically change the interaction of economic agents, one can choose another alternative way to achieve a desired or a superior level of future economic effect. The designer's approach allows to accelerate achieving this result, as well as to reduce systemic clashes and ensure saving transaction costs.

In terms of logistics it is important to find the right material flow of a certain quality and required quantity with minimal costs just in the right time and place [5]. However, urban passenger flows, in aggregate, slow down the transportation process, as well as the turnover of economic resources.

Digitalization changes the usual models of interactions and considers economic agents as equal participants. The logistics management system turns into the information space [6],

\footnotetext{
* Corresponding author: glebsavin@ya.ru
} 
with adaptive intelligent systems available there being a greater control over the organization, management and optimization of flow processes [7]. In addition, today, a shared economy and network interactions are developing. They are designed to transform the usual interactions between economic agents, ensuring the most efficient use of assets and targeted development of innovative production complexes at a lower level of transaction costs.

Thus, within the context of evolutionary-institutional economic theory, digital logistics acts as a new approach to optimizing flow processes today, which allows us to consider the problem of their adaptive coordination in a comprehensive manner, taking into account the information and communication technologies introduced into the transport and logistics systems of a smart city, developing a service, contributing to growing trust, cooperation and engagement in the framework of appropriate infrastructure.

\section{Materials and Methods}

Nowadays most of the initiatives in the TLS of a smart city are associated with the development of digital platforms [1-3]providing a more convenient access and a high level of service. At the same time, the development of transport business models based on the principle of a shared economy leads to reducing transaction costs for economic agents. We can observe a similar result in supply chains due to ERP II, SCRP and other optimization and management technologies.

All initiatives require a high speed of information transfer, as well as its reliability and mechanisms of assessment, accounting, storage and distribution [8]. In this regard, the development of sensor technologies, cloud computing, contactless information collection, the Internet of things, intelligent systems is a necessary basis to make a new type of transport and logistics system.

The question arises, «How can one improve the key indicators of coordination of streaming processes?»

Option 1 is to change the current norms and rules for the interaction of economic agents in the digital economy, which has not been fully developed now.

Option 2 is to use the currently developed models in the transport and logistics system.

Option 3 is to do a comparative genetic analysis and then select, adapt, improve and implement a new model of coordination of flow processes in the current circumstances, new development institutions added.

Each option is characterized by many variations in development based on current cumulative factors (personality, psychophysiology, emotional thinking, road environment, condition of vehicles, training, etc.) and development criteria (population size, macroeconomic factors, current problems, organization methods, basic sectors of the economy, the level of transaction costs) [9].

When assessing the TLS, the choice of each option requires adjusting norms and rules for them to meet the needs of economic agents.

\section{Results and Discussion}

The present rules of interaction are expressed by the institutional environment of the TLS of a smart city in the field of regulation, organization and provision, but they do not allow to develop a transport and logistics system of a new type for the lack of a systematic approach and no use of digital logistics, which contribute to the adaptive coordination of streaming processes. 
All present options (types) of TLS development for a smart city are viable and should be justified when choosing the appropriate vector for their formation (Figure 1).

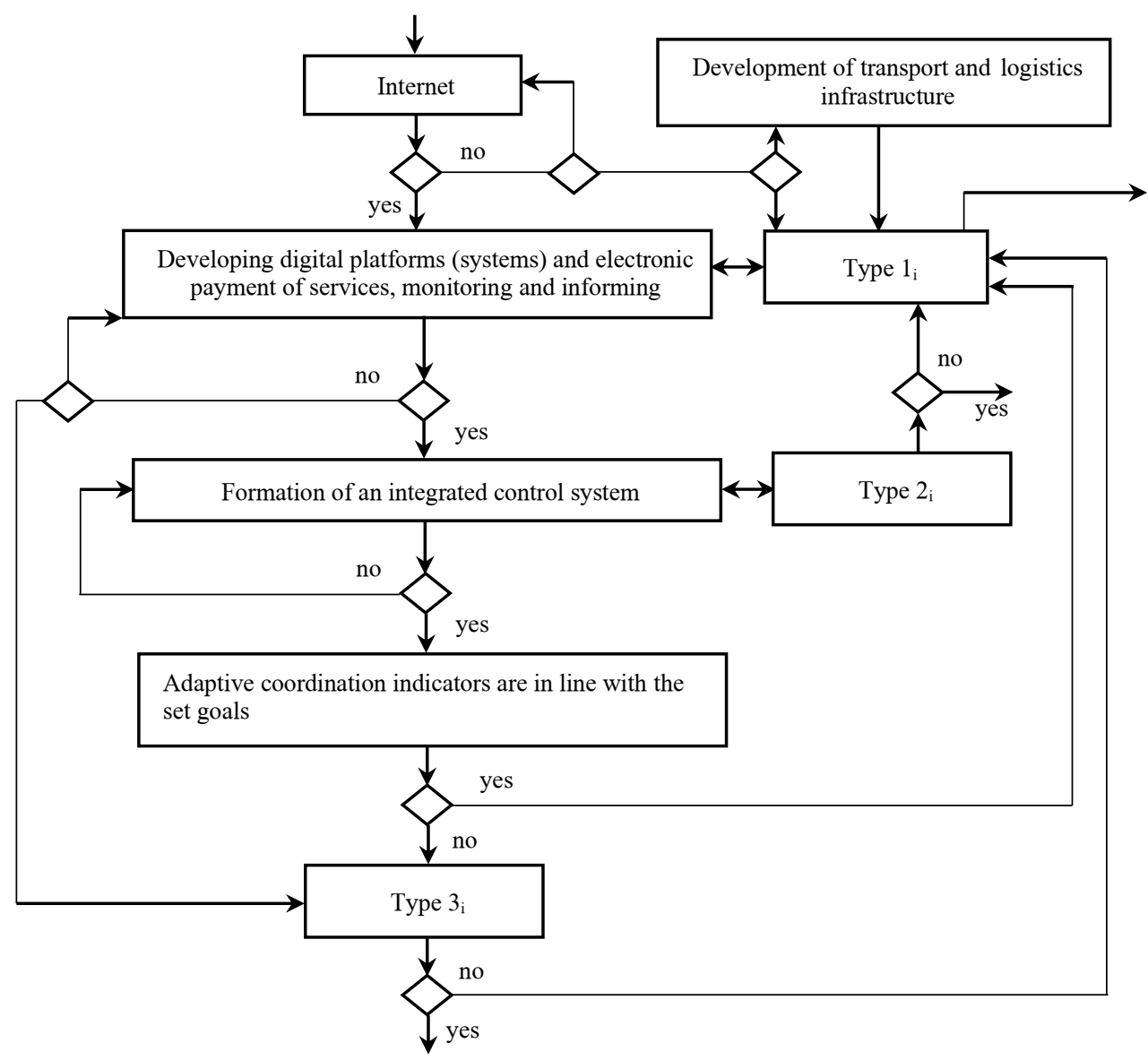

Fig. 1 Algorithm for choosing the path of development of the transport and logistics system of a smart city

The basis for the functioning of the TLS of a smart city is digital and intellectual infrastructure providing a scheduled speed of information transfer to meet the needs of economic agents and contributing to the development of coordination of streaming processes during the phased development of digital platforms and services, and the formation of an integrated control system.

Development of a new model for coordinating streaming processes requires a deeper study of it, as well as the formation of new norms and rules for the interactions of economic agents in the information space of the TLS of a smart city. Their development is provided by formal and informal institutions, the latter also change in the context of the shared economy and network interactions. In the digital world, transactions in case of equal economic agents, as well as decentralization of economic resources form a new model of economic relations.

Let us single out the norms of interactions depending on the stages of development of the TLS of a smart city (Table 1). 
Table 1. Norms of TLS interactions in a smart city

\begin{tabular}{|c|c|}
\hline Type & Comments \\
\hline 1 a & $\begin{array}{l}\text { You can regulate interactions between economic agents on the Internet, provide legal } \\
\text { regulation, responsibility, information protection, control of the speed and quality of } \\
\text { transmitted information, as well as clarify the legal status of Smart contracts, crawling, } \\
\text { biometric information, etc. }\end{array}$ \\
\hline $1 \sigma$ & $\begin{array}{l}\text { The main regulatory framework for transport infrastructure and traffic management is } \\
\text { formed. }\end{array}$ \\
\hline $1_{\mathrm{B}}$ & The transport process of transportation of goods and passengers is regulated. \\
\hline $1_{\mathrm{r}}$ & The basics of relationships in trade and logistics are explained and regulated. \\
\hline $2 \mathrm{a}$ & $\begin{array}{l}\text { The basic requirements to the architecture of the traffic management system, collection, } \\
\text { analysis, storage and distribution of information are met. Besides, the necessary elements } \\
\text { for the formation of an intelligent transport system, depending on the population of the city, } \\
\text { is provided. }\end{array}$ \\
\hline 2 б & $\begin{array}{l}\text { At the level of the enterprise and the supply chain, rules for interaction between participants } \\
\text { in economic activity are formulated. }\end{array}$ \\
\hline $3 \mathrm{a}$ & New development institutions in the field of digital logistics are formed. \\
\hline
\end{tabular}

In the future developing the TLS of smart city type 3 will provide control over the organization of transportation in real time, savings for the participants of streaming processes with a rational choice of a method of transportation and involving consumers in management, as well as a higher level of coordination of economic agents.

\section{Conclusion}

In the modern digital world resources are being diverted from traditional economic mechanisms, while information and communication technologies give impetus to forming new development institutions that ensure the transition to a new technological mode of economic development in the decentralized economic resources environment, contributing to a new quality of human life.

Nowadays, there is a need to control decentralized systems through the formation of an institutional environment for TLS of a smart city, and a more flexible approach is needed to reduce systemic conflicts and coordinate interaction of economic agents.

As a result, for each type today, there have been partially formed institutions that determine the interaction between economic agents, but for a deeper integration we need new ones providing adaptive coordination of flow processes. Their transformation has a direct structural relationship with a quantitative indicator or a set of economic agents with growing trust and cooperation, which is implemented when using digital logistics.

\section{References}

1. X. Jiang, Journal of Chinese Economic and Business Studies, 18, 333 (2020)

2. M. Attaran, Supply Chain Forum: An International Journal, 21, 158 (2020)

3. A. Nixa, S. Deckerb, Business History, 04, 1 (2021)

4. A. Lagorio, G. Zenezini, G. Mangano, R. Pinto, International Journal of Logistics Research and Applications, 11, 1 (2020)

5. S. Winkelhaus, E. Grosse, Journal of Production Research, 58, 18 (2020)

6. G. Savin. Smart city logistics, E3S Web of Conferences, 208 (2020) 
7. T. Yigitcanlar, Md. Kamruzzaman, Journal of Urban Technology, 26, 21 (2019)

8. G. Savin, S. Bronnikov, Business Logistics in Modern Management, 485 (2018)

9. G. Grossi, D. Pianezzi, International Journal of Urban Policy and Planning, 69, 79 (2017) 